\begin{tabular}{c} 
Brazilian Journal \\
of Chemical \\
Engineering \\
\hline
\end{tabular}

ISSN 0104-6632

Printed in Brazil

www.abeq.org.br/bjche

Vol. 32, No. 01, pp. 23 - 33, January - March, 2015

dx.doi.org/10.1590/0104-6632.20150321s00003146

\title{
EVALUATION OF COMPOSITION, CHARACTERIZATION AND ENZYMATIC HYDROLYSIS OF PRETREATED SUGAR CANE BAGASSE
}

\author{
A. A. Guilherme ${ }^{1 *}$, P. V. F. Dantas ${ }^{1}$, E. S. Santos ${ }^{1}$, F. A. N. Fernandes ${ }^{2}$ and G. R. Macedo ${ }^{1}$ \\ ${ }^{1}$ Department of Chemical Engineering, Federal University of Rio Grande do Norte, \\ UFRN, Av. Senador Salgado Filho 3.000, Campus Universitário, Lagoa Nova, Bloco 16, \\ Unidade II, 59.078-970, Natal - RN, Brazil. \\ Phone: + (55) 843215 3769, Fax: + (55) 8432153770 \\ E-mail: alexandredearaujoguilherme@gmail.com \\ ${ }^{2}$ Department of Chemical Engineering, Federal University of Ceará, UFC, Campus do Pici, \\ Bloco 709, 60455-760, Fortaleza - CE, Brazil.
}

(Submitted: December 2, 2013 ; Revised: March 28, 2014 ; Accepted: March 31, 2014)

\begin{abstract}
Glucose production from sugarcane bagasse was investigated. Sugarcane bagasse was pretreated by four different methods: combined acid and alkaline, combined hydrothermal and alkaline, alkaline, and peroxide pretreatment. The raw material and the solid fraction of the pretreated bagasse were characterized according to the composition, SEM, X-ray and FTIR analysis. Glucose production after enzymatic hydrolysis of the pretreated bagasse was also evaluated. All these results were used to develop relationships between these parameters to understand better and improve this process. The results showed that the alkaline pretreatment, using sodium hydroxide, was able to reduce the amount of lignin in the sugarcane bagasse, leading to a better performance in glucose production after the pretreatment process and enzymatic hydrolysis. A good xylose production was also observed.

Keywords: Sugarcane; Bagasse; Pre-treatment; Enzymatic hydrolysis.
\end{abstract}

\section{INTRODUCTION}

Agricultural residues, such as sugarcane bagasse (Hofsetz and Silva, 2012), are rich in lignocellulosic biomass, which is mainly composed of cellulose, hemicellulose and lignin. Sugarcane bagasse, the major by-product of the sugarcane industry, is a very promising raw material for the production of glucose, xylose, ethanol and methane.

The production of ethanol from lignocellulosic materials requires three main steps. The lignocellulosic material has to be pretreated to allow higher conversion of cellulose, which is consumed during enzymatic hydrolysis to produce glucose and xylose that are finally fermented to produce ethanol (Sun and Cheng, 2002; Bommarius et al., 2008).

The pretreatments act by disrupting the lignocellulosic matrix, reducing the amount of lignin and hemicellulose and modifying the crystalline structure of cellulose to make it more susceptible to enzymatic attack (Silverstein et al., 2007). The yield of conversion of lignocellulosic materials into glucose is usually very low if the enzymatic hydrolysis is carried out without applying a pretreatment. Pretreatments are applied when a high yield of conversion into glucose is intended from the enzymatic hydrolysis of

*To whom correspondence should be addressed 
the solid fraction of the pretreated bagasse. The liquid fraction produced by the pretreatment process is rich in sugars (mainly pentoses) that can also be used to produce ethanol. Lignin can be used to produce energy (Luo et al., 2010).

Pretreatments with sulfuric, nitric or hydrochloric acid can solubilize hemicelluloses, exposing the cellulose to enzymatic attack (Schell et al., 2003). Alkaline pretreatments remove lignin and reduce the degree of cellulose crystallinity (Chang and Holtzapple, 2000).

Pretreatments with peroxides, at alkaline $\mathrm{pH}$, improve the enzymatic efficiency through oxidative delignification and decrease the crystallinity of the cellulose (Gould, 1985). This pretreatment is known to reduce the production of polluting wastes and inhibitory compounds of enzymatic hydrolysis (Rabelo et al., 2011).

The hydrothermal pretreatment is based on the use of water (or water vapor) and heat (150 to $230{ }^{\circ} \mathrm{C}$ ) to produce hydrolyzed hemicellulose derivatives and a solid fraction composed of lignin and cellulose. This process has the advantage of not using acid catalysts (preventing corrosion of process equipment) and to produce less inhibitory compounds for the enzymatic hydrolysis (Boussasar et al., 2009).

Several characteristics of the solid fraction of pretreated biomass have been studied by many researchers. External morphology, the main organic groups that constitute the biomass and the crystallinity of the cellulose molecule have been addressed. The external morphology of the biomass can be studied by scanning electron microscopy (SEM) methodology (Reiner, 2010). Riyajan and Intharit (2011) studied the morphology of sugarcane bagasse subjected to a combined sodium hydroxide and silane pretreatment, showing that the surface of raw bagasse exhibited lower roughness when compared with the pretreated bagasse, which was caused by the removal of fatty acids from the surface of the bagasse. Morphological studies with green coconut, soybean straw, wheat bran, rice hulls, sugarcane bagasse and cashew apple have also been carried out after different pretreatments (Brigida et al., 2010; Xu et al., 2007; Zhao et al., 2010; Camargo et al., 2012 and Rocha, 2010).

FTIR can be used to characterize the biomass according to its organic groups (Smith, 1996). The main result of FTIR assays is associated with lignin. It is an aromatic biopolymer constituted mainly of phenylpropane substituted units bonded together to form a polymer of low regularity, crystallinity and optical activity. Although about 20 types of bonds exist within lignin, the largest number is related to links between ether bonds (Sun et al., 2000). The solid component of lignin is a key factor for the success of the saccharification process because lignin is considered to be an adsorbent of cellulolytic enzymes. Phenolic hydroxyl groups have an inhibitory effect on cellulases and it is important to reduce the amount of these groups during pretreatment (Gould, 1985; Pan, 2008). Gou et al. (2009) have studied the enzymatic saccharification of three different feedstocks (rice straw, bagasse and silvergrass) that were pretreated with different acid concentrations. The study verified that the enzymatic saccharification was affected by the lignin composition of the raw materials.

The cellulose molecule is formed by a crystalline part and an amorphous part. The cellulose crystallinity is an important factor that can enhance the results obtained from the enzymatic hydrolysis (Chang and Holtzapple, 2000). The crystallinity can be quantified by X-ray diffraction (Cullity, 1956). The lignocellulosic biomass crystallinity represents the relative amount of overall crystalline cellulose in the solid fraction of the biomass. Thus, it is strongly influenced by the biomass composition. Rodrigues et al. (2007) studied the methylcellulose crystallinity from purified sugarcane bagasse and found some modification in the samples.

The objective of this work was to apply different pretreatments to sugarcane bagasse and to correlate the chemical composition, crystallinity index, external morphology, and organic groups of the material with the results obtained for glucose production when enzymatic hydrolysis is applied.

\section{MATERIAL AND METHODS}

\section{Sugarcane Bagasse}

The sugarcane bagasse was provided by Usina Estivas (Arés - RN, Brazil). The bagasse contained $50 \%(\mathrm{w} / \mathrm{w})$ of humidity and $2 \%(\mathrm{w} / \mathrm{w})$ of reducing sugars. The bagasse was dried, prior to applying the pretreatments, in a circulating drying oven (Tecnal model TE-394/1, Piracicaba/Brazil) at $40{ }^{\circ} \mathrm{C}$ until a final humidity of $5 \%$ (wet basis) was reached. The bagasse was ground and sieved. The experiments were carried out with particles smaller than $0.84 \mathrm{~mm}$.

\section{Enzymes}

The enzymes NS22074 (cellulases complex) and NS50010 ( $\beta$-glucosidase enzyme) were used in this work. The enzymes were kindly donated by Novozymes (Bagsvaerd, Denmark). 


\section{Pretreatment Study}

Figure 1 summarizes the steps followed in this study. Four pretreatments were studied: combined acid and alkaline, combined hydrothermal and alkaline, alkaline and hydrogen peroxide pretreatments. At first, the acid pretreatment was idealized because it is the most studied pretreatment (Schell et al., 2003). The importance given to lignin removal led to the study of a second step using an alkaline pretreatment that was applied after the acid pretreatment (Chang and Holtzapple, 2000). Thus, a combined pretreatment with acid in a first step and alkali in a second step was carried out. To reduce the acidic waste, avoid acid corrosion of the equipment and improve the glucose production, a second pretreatment (combined hydrothermal and alkaline) was carried out and compared to the first pretreatment.

A third pretreatment solely with sodium hydroxide was tested to reduce the number of processing steps. In this case, only lignin removal was expected and the results of composition, characterization and glucose production after enzymatic hydrolysis were evaluated for hydrolysis with higher hemicellulose content in the pretreated bagasse. A fourth pretreatment process with hydrogen peroxide in an alkaline medium was applied to compare with the pretreatment using solely sodium hydroxide, aiming to reduce the amount of waste and of inhibitory compounds that might affect the enzymatic hydrolysis (Rabelo et al., 2011).

The amount of solid fraction of the pretreated bagasse was quantified after each pretreatment process using Equation (1). This value is important to evaluate the pretreatment process in relation to the reduction of lignin and hemicellulose.

$$
\begin{aligned}
& \text { Solid fraction }\left(\frac{\mathrm{g}}{\mathrm{g} \text { raw material }}\right) \\
& =\frac{\text { Final amount of insoluble part }(\mathrm{g})}{\text { Inicial amount of raw material }(\mathrm{g})}
\end{aligned}
$$

\section{Combined Acid and Alkaline Pretreatment}

The first step of the pretreatment was carried out using $20 \%(\mathrm{w} / \mathrm{v})$ of bagasse immersed in a $2 \%(\mathrm{v} / \mathrm{v})$ or $3.66 \%(\mathrm{w} / \mathrm{w})$ sulfuric acid solution. The mixture was subjected to a temperature of $121^{\circ} \mathrm{C}$ for $30 \mathrm{~min}$ (Guo et al., 2009). The resulting solid fraction was washed until pH 7.0 and then it was dried at $40{ }^{\circ} \mathrm{C}$ in a circulating drying oven (Tecnal model TE-394/1, Piracicaba/Brazil).

The second step of this pretreatment was carried out using $20 \%(\mathrm{w} / \mathrm{v})$ of bagasse immersed in a $4 \%$ $(\mathrm{w} / \mathrm{w})$ sodium hydroxide solution. The mixture was also subjected to a temperature of $121^{\circ} \mathrm{C}$ for $30 \mathrm{~min}$ (Vasquez et al., 2007). The $\mathrm{pH}$ of the mixture was adjusted to 7.0 using $\mathrm{HCl}$ after the reaction. The solid fraction was washed three times with tap water to remove dissolved sugars and solubilized lignin, and stored at $4{ }^{\circ} \mathrm{C}$ until used. Before the use of the bagasse in assays, the humidity was measured to convert amounts to a dried weight basis.

\section{Combined Hydrothermal and Alkaline Pretreatment}

The hydrothermal pretreatment was carried out using a high-pressure reactor (Stainless Steel PARR Reactor 4520-1 L, Series 4520 Bench Top Reactors 1 L Parr Instruments Company, USA), 10\% of solids, $100 \mathrm{rpm}, 20$ bar of initial pressure with nitrogen, $170{ }^{\circ} \mathrm{C}$ of process temperature reaching $35 \mathrm{bar}$; the rise time of the temperature was 40 minutes, the process time was 40 minutes and the cooling time was 15 minutes. Because this process did not use acid catalysts, preventing corrosion of process equipment, and producing less inhibitory compounds of enzymatic hydrolysis (Boussasar et al., 2009), the solid fraction was not washed. The resulting solid fraction was dried at $40{ }^{\circ} \mathrm{C}$ in a circulating drying oven (Tecnal model TE-394/1, Piracicaba/Brazil). The second step of the pretreatment was carried out under the same conditions as presented in the second step of the combined acid and alkaline pretreatment.

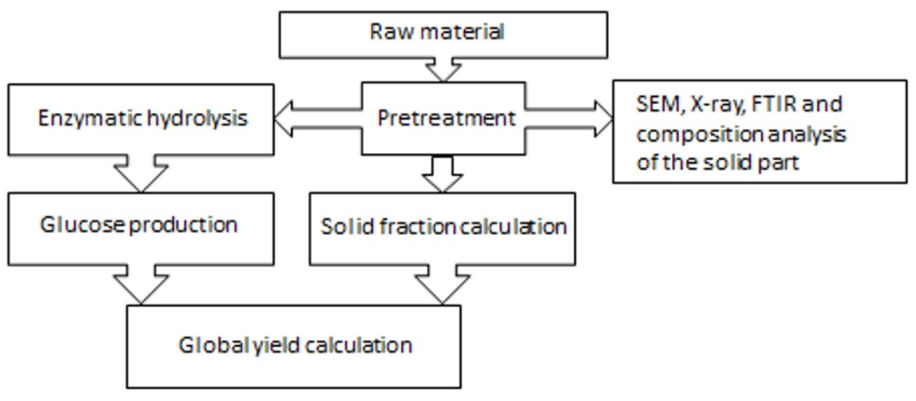

Figure 1: Steps of this study. 


\section{Alkaline Pretreatment}

This pretreatment was carried out under the same conditions employed in the second step of the combined acid and alkaline pretreatment.

\section{Peroxide Pretreatment}

The pretreatment with hydrogen peroxide was carried out using $4 \%(\mathrm{w} / \mathrm{v})$ of biomass immersed in a $7.35 \%(\mathrm{v} / \mathrm{v})$ or $8.15 \%(\mathrm{w} / \mathrm{w})$ hydrogen peroxide solution. The $\mathrm{pH}$ of the hydrogen peroxide solution was adjusted to 11.5 with sodium hydroxide. The mixture was stirred at $100 \mathrm{rpm}$ for $1 \mathrm{~h}$ at room temperature using a mechanical stirrer (Tecnal model TE-139, Piracicaba/Brazil) (Rabelo et al., 2011). Due to the exothermic nature of the process, a temperature increase was observed and the final temperature was $80{ }^{\circ} \mathrm{C}$. After the reaction, the liquid fraction was discarded and the solids washed with water (Rabelo et al., 2011). The solid fraction was washed fifteen times with tap water and stored at $4{ }^{\circ} \mathrm{C}$ until used. Before the use of the bagasse in assays, the humidity was measured to convert amounts to a dried weight basis.

\section{Sugarcane Bagasse Composition and SEM, X-Ray Diffraction and FTIR Characterization}

Cellulose, hemicellulose, lignin, ash, organic solvent extractives, and hot water extractives $\left(100{ }^{\circ} \mathrm{C}\right)$ contents were quantified in the raw material and in the solid fraction of the pretreated bagasse.

The amounts of cellulose, hemicellulose, lignin and ashes were determined according to the methods described by Gouveia et al. (2009). Determinations of organic solvent and hot water extractives were carried out according to the NREL procedure (National Renewable Energy Laboratory, Golden, Colorado USA) (Sluiter et al., 2008) with some modifications; quantification of hot water extractives (sugars, HMF, furfural and organics acids) was carried out by HPLC. All characterizations were assayed in triplicate.

Scanning electron microscopy (SEM) was used to observe the morphology of the raw and pretreated bagasse to evaluate the changes in the external structure caused by the pretreatments (Phillips XL-30 ESEM, USA). SEM was carried out using a voltage of $20 \mathrm{kV}$ and working distance of $10 \mathrm{~mm}$, spot size of 4.0, SE detector and metallizer (SCD-Bal-Tec 005, USA).

FTIR analysis was used to detect the presence of the main organic groups that constitute the lignocellulosic structure. FTIR analysis was carried out in the range of 650 to $4000 \mathrm{~cm}^{-1}$ using a Fourier Transform infrared spectrophotometer (Spectrun 65 FT-IR, Perkin Elmer, USA). Thus, it was possible to detect the changes caused by the pretreatments in relation to the content of lignin and hemicellulose.

The crystallinity of the cellulose fiber was evaluated by X-Ray Diffraction (XRD-6000, Shimadzu, Japan). Copper Ka radiation, $30.0 \mathrm{kV}$ of voltage and $15 \mathrm{~mA}$ of electric current, and a rate of 2.0 degrees per minute for a $2 \theta$ continuous scan from 4.0 to 70.0 degrees were applied. This analysis allowed the detection of the amorphous part of the lignocellulosic biomass, as well as the modification of the crystalline structure of the cellulose. The crystallinity index (CI) was obtained from the ratio of the maximum peak intensity $002\left(\mathrm{I}_{002}, 2 \theta=22.5\right)$ and minimal depression $\left(\mathrm{I}_{\mathrm{am}} 2 \theta=18.5\right)$ between peaks 001 and 002 (Segal et al., 1959; Rodrigues et al., 2007) according to Equation (2).

$$
\mathrm{CI}(\%)=\frac{\mathrm{I}_{002}-\mathrm{I}_{\mathrm{am}}}{\mathrm{I}_{\mathrm{am}}} \times 100
$$

where $I_{002}$ is the maximum intensity of the 002 peak and $\mathrm{I}_{\mathrm{am}}$ the minimal depression of the amorphous structure.

\section{Enzymatic Hydrolysis}

The assays were conducted to evaluate the amount of cellobiose and glucose resulting from each pretreatment. However, because a high amount of hemicellulose remained in some of the pretreated bagasse, the amount of xylose was also quantified. The assays were performed in a shaker (TE - 421, Tecnal, Sao Paulo / Brazil) at $150 \mathrm{rpm}$ and $50{ }^{\circ} \mathrm{C}$ using Erlenmeyers of $250 \mathrm{~mL}$. A reaction volume of $30 \mathrm{~mL}$ of $50 \mathrm{mM}$ citrate buffer at pH 4.8 was used. An amount of pretreated bagasse representing 4.0\% $(\mathrm{w} / \mathrm{v})$ of cellulose in the reaction medium was used in the enzymatic reactions. A solution of sodium azide $(1 \% \mathrm{w} / \mathrm{w})$, at a $1: 100(\mathrm{v} / \mathrm{v})$ ratio, was used to prevent microorganism growth. An enzyme load corresponding to $27 \mathrm{FPU} / \mathrm{g}$ of cellulose (NS22074 enzyme) and $4 \mathrm{CBU} / \mathrm{g}$ of cellulose (NS50010 enzyme) was applied. The assays were carried out for $48 \mathrm{~h}$ and done in triplicate.

After hydrolysis, the samples were subjected to $100{ }^{\circ} \mathrm{C}$ for $10 \mathrm{~min}$ for enzyme inactivation (Benko et al., 2008). The samples were centrifuged at $14000 \mathrm{rpm}$ (18406.7 x g) (EPPENDORF model 5424, Germany) for $30 \mathrm{~min}$, filtered in a PES (polyethersulfone) membrane of $0.22 \mu \mathrm{m}$ (TPP, Switzerland) and then stored 
at $-20{ }^{\circ} \mathrm{C}$. The amounts of cellobiose, glucose and $\mathrm{xy}-$ lose were quantified by HPLC according to the analytical procedures.

The global yield of glucose and xylose produced from raw material after pretreatment and enzymatic hydrolysis was quantified with Equation (3) using the result of solid fraction obtained by Equation (1).

Global yield $\left(\frac{\mathrm{g} \text { sugar }}{100 \mathrm{~g} \text { raw material }}\right)=$

$$
\text { Solid fraction } \mathrm{x} \frac{\text { Sugar }(\mathrm{g})}{\begin{array}{c}
\text { Initial amount of } \\
\text { pretreated bagasse }(\mathrm{g})
\end{array}} \times 100
$$

\section{Analytical Procedures}

The amounts of sugars, HMF, furfural and organic acids were obtained by HPLC using a Shimpack SCR 101-H column (SHIMADZU, Kyoto/Japan) at $65^{\circ} \mathrm{C}, 5 \mathrm{mM}$ sulfuric acid in MilliQ water (Barnstead EasyPure RF System model D7031, Iowa/EUA) as eluent, a flow rate of $0.6 \mathrm{~mL} / \mathrm{min}$ and a refraction index detector (SHIMADZU model RID-10A, Japan).

The amount of digested cellulose (conversion of cellulose into cellobiose and glucose) was determined according to the NREL digestibility protocol of lignocellulosic biomass subjected to pretreatments (Seling et al., 2008) according Equations (4) and (5).

$(\%)$ Conversion $=\frac{\text { Digested celulose }(\mathrm{g})}{\text { Added celulose }(\mathrm{g})} \times 100$

Digested celulose $(\mathrm{g})=($ Re action volume $(\mathrm{L}))$

$$
\begin{aligned}
& \mathrm{x}(\text { Glu cose }(\mathrm{g} / \mathrm{L}) \times 0.9 \\
& + \text { Cellobiose }(\mathrm{g} / \mathrm{L}) \text { x 0.95) }
\end{aligned}
$$

\section{RESULTS AND DISCUSSION}

The amounts of solid fraction obtained after the pretreatment processes were $0.26,0.33,0.55$ and $0.21 \mathrm{~g} / \mathrm{g}$ raw material respectively for the combined acid and alkaline, combined hydrothermal and alkaline, alkaline, and peroxide pretreatment. The higher amount of solid fraction in the alkaline pretreatment was caused by the low conversion of hemicellulose, which remained in the solid fraction (Table 1). A considerable amount of foam was formed during the hydrogen peroxide pretreatment and this foam influenced the high loss of biomass observed in this pretreatment. The small amounts of solid fraction that were observed were caused by the solubilization of part of the bagasse in the liquid fraction.

Table 1 presents the composition of the raw material and the solid fraction of the pretreated sugarcane bagasse. The combined acid and alkaline pretreatment and the combined hydrothermal and alkaline pretreatment were able to increase by 68.5 and $61.0 \%$, respectively, the amount of cellulose in the bagasse composition.

The combined acid and alkaline pretreatment and the combined hydrothermal and alkaline pretreatment were able to reduce the amount of hemicellulose in the bagasse by 60.7 and $58.7 \%$, respectively. All pretreatments were able to reduce the amount of lignin by at least $50 \%$, with the alkaline pretreatment presenting the highest lignin reduction (75.8\%).

The pretreatments applied in this work gave results similar to those presented in the literature (Benko et al., 2008; Silva et al., 2011; Asgher et al., 2013). The exception was for the peroxide pretreatment that presented less cellulose and more hemicellulose than the results presented by Rabelo et al., (2011).

The results obtained by applying the hydrothermal pretreatment were similar to those obtained for other biomass such as grape stalks, corn stalks, grass (Cynodon dactylon), sorghum, wood, olive tree prunings, eucalyptus, bamboo, wheat straw and sugarcane bagasse (Amendola et al., 2012; Egues et al., 2012; Lee et al., 2009; Rohowsky et al., 2013; Chen et al., 2010; Martin et al., 2010; Alves et al., 2010; Ruiz et al., 2013a; Ruiz et al., 2013b; Abril et al., 2012).

Figure 2 shows the results of the morphological analysis of the raw material and solid fraction of the pretreated bagasse by SEM. The morphologies of the bagasse that were subjected to the combined acid and alkaline pretreatment and the combined hydrothermal and alkaline pretreatment were very similar, but presented subtle differences when compared to the alkaline and to the peroxide pretreatment. The morphologies of the bagasse that were subjected to the alkaline pretreatment and the peroxide pretreatment were similar. These results reflect the effect of the different pretreatments on the bagasse morphology when more or less lignin and hemicellulose are solubilized. Figure 2 also shows that a more disorganized structure results from the application of the pretreatments compared to the raw material. 
Table 1: Composition of the raw material and the solid fraction of pretreated bagasse (dried basis).

\begin{tabular}{|l|c|c|c|c|c|c|}
\hline \multicolumn{1}{|c|}{ Pretreatment } & $\begin{array}{c}\text { Cellulose } \\
\mathbf{( \% )}\end{array}$ & $\begin{array}{c}\text { Hemicellulose } \\
\mathbf{( \% )}\end{array}$ & $\begin{array}{c}\text { Total lignina } \\
\mathbf{( \% )}\end{array}$ & $\begin{array}{c}\text { Organic solvent } \\
\text { extractives } \\
(\%)\end{array}$ & $\begin{array}{c}\text { Hot water } \\
\text { extractives } \\
(\%)\end{array}$ & $\begin{array}{c}\text { Ashes } \\
\mathbf{( \% )}\end{array}$ \\
\hline None (raw material) & $38.59 \pm 3.45$ & $27.89 \pm 2.68$ & $17.79 \pm 0.62$ & $1.61 \pm 0.16$ & $1.11 \pm 1.23$ & $8.80 \pm 0.02$ \\
Combined acid and alkaline & $65.03 \pm 2.34$ & $10.95 \pm 0.19$ & $8.12 \pm 0.31$ & $0.98 \pm 0.61$ & $10.97 \pm 0.98$ & $4.60 \pm 0.76$ \\
Combined hydrothermal and & $62.14 \pm 4.12$ & $11.52 \pm 0.73$ & $7.87 \pm 1.88$ & $0.77 \pm 0.09$ & $10.08 \pm 0.58$ & $8.10 \pm 0.06$ \\
alkaline & $47.21 \pm 3.23$ & $29.29 \pm 2.32$ & $4.31 \pm 1.78$ & $1.22 \pm 0.47$ & $12.52 \pm 0.53$ & $6.05 \pm 1.22$ \\
$\quad$ Alkaline & $53.85 \pm 2.76$ & $22.02 \pm 3.27$ & $7.99 \pm 3.84$ & $0.78 \pm 1.33$ & $10.65 \pm 1.55$ & $4.22 \pm 1.27$ \\
\hline
\end{tabular}

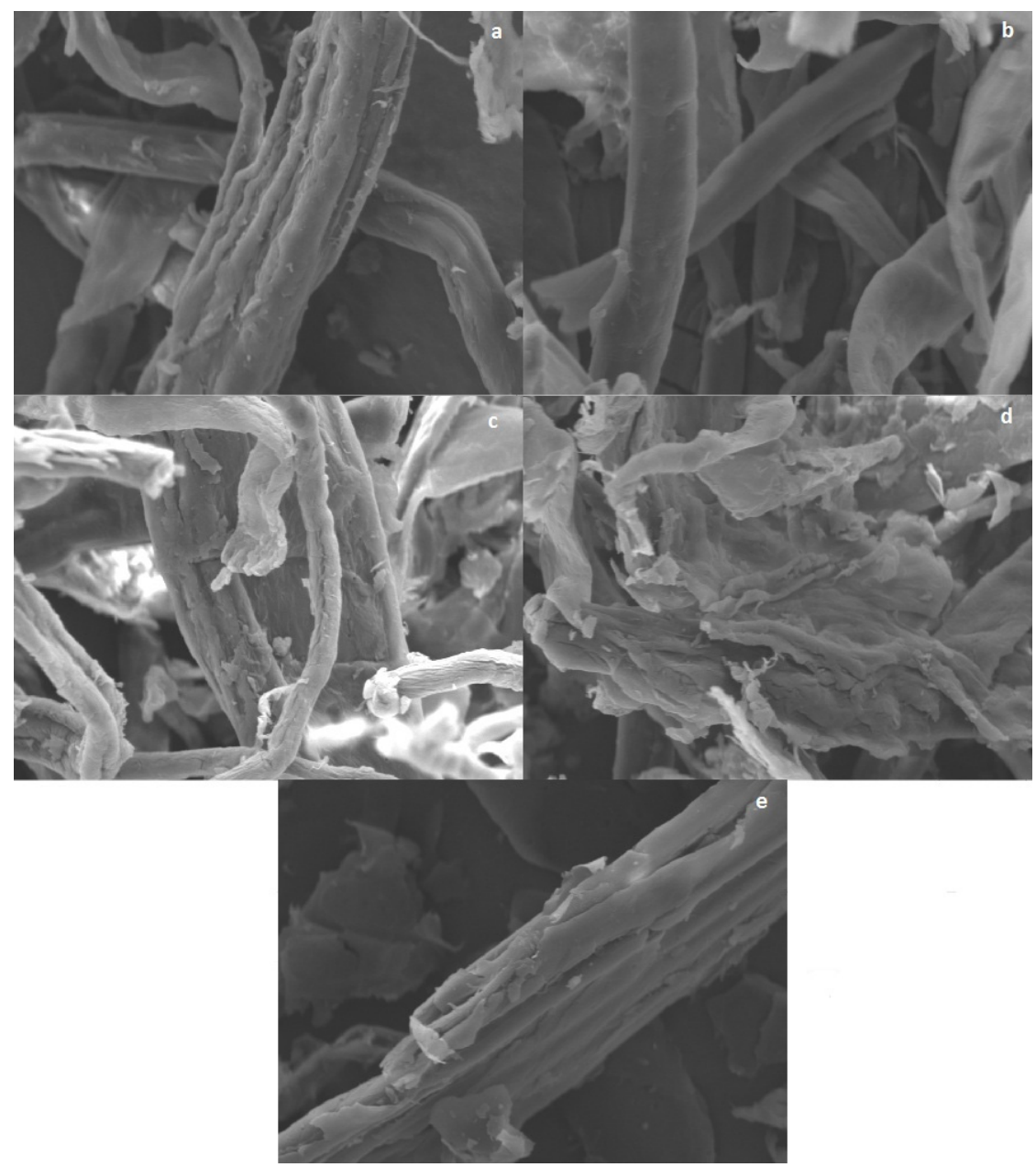

Figure 2: Morphology of the raw material and of the solid fraction after the pretreatment processes of the sugarcane bagasse by SEM analysis. (a) bagasse after combined acid and alkaline pretreatment; (b) bagasse after combined hydrothermal and alkaline pretreatment; (c) bagasse after alkaline pretreatment; and (d) bagasse after peroxide pretreatment; and (e) raw material.

Figure 3 presents the results of the FTIR analysis of the raw and pretreated bagasse. The band at $3350 \mathrm{~cm}^{-1}$ $(\mathrm{O}-\mathrm{H})$ was more intense in the combined acid and alkaline pretreatment, combined hydrothermal and alkaline pretreatment and in the peroxide pretreat- ment than in the alkaline pretreatment and in the raw material. A similarity in the bands at $2900 \mathrm{~cm}^{-1}$ could be observed for the raw material, combined hydrothermal and alkaline and the alkaline pretreatment, but was more intense for the other pretreatments. 
The band at $1710 \mathrm{~cm}^{-1}$ (HO-C=O carboxylic acid) was only found in the raw material. The band at $1620 \mathrm{~cm}^{-1}(\mathrm{C}=\mathrm{O}$ ketone $)$ presented the same intensity in the raw material and in the combined acid and alkaline pretreatment, but was more intense in the peroxide pretreatment and less intense in the other pretreatments.

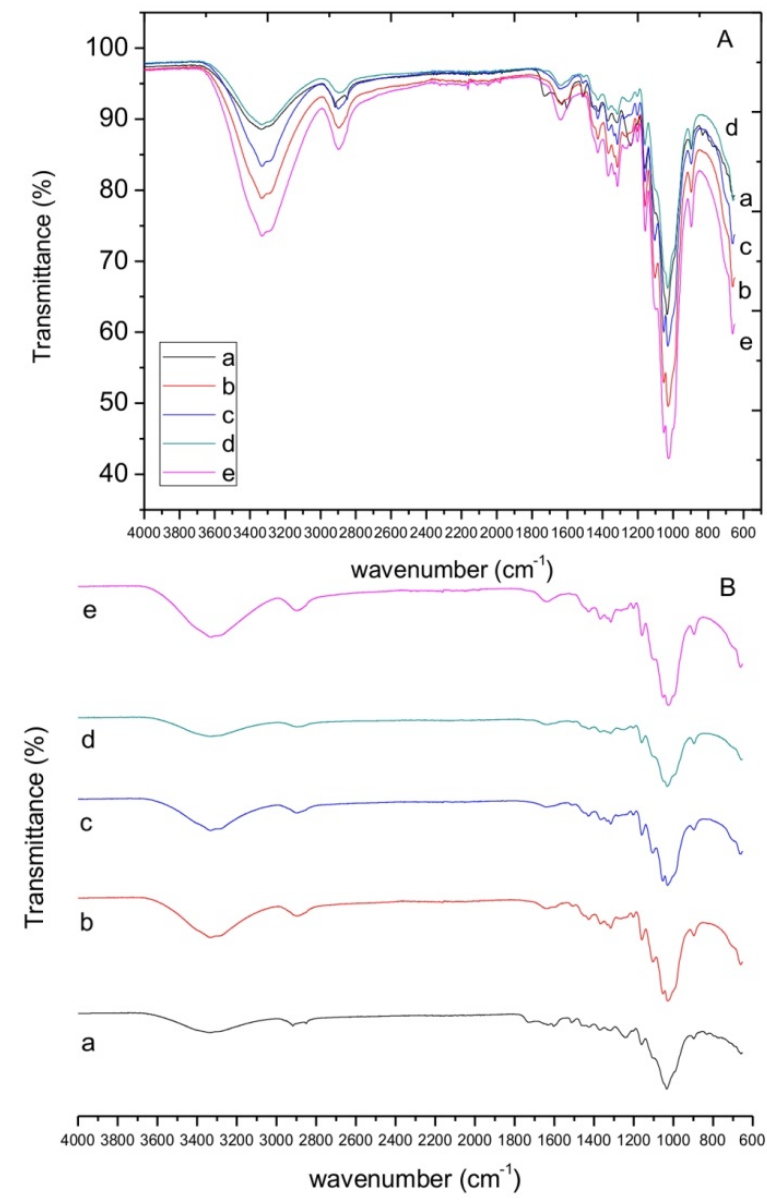

Figure 3: FTIR analysis of the raw material and of the solid fraction after the pretreatment processes of the sugarcane bagasse: (A) overlapping spectra; (B) stacked spectra; (a) raw material; (b) bagasse after combined acid and alkaline pretreatment; (c) bagasse after combined hydrothermal and alkaline pretreatment; (d) bagasse after alkaline pretreatment; and (e) bagasse after peroxide pretreatment.

The bands at 1600,1500 and $1410 \mathrm{~cm}^{-1}(\mathrm{C}-\mathrm{H}$ vibration of aromatic ring) had different intensities for all pretreated and raw materials. The bands at 1390 and $1360 \mathrm{~cm}^{-1}$ (O-H phenolic) were more intense in the combined acid and alkaline, in the combined hydrothermal and in the alkaline and peroxide pretreatments. The band at $1250 \mathrm{~cm}^{-1}(\mathrm{C}-\mathrm{C})$ was more intense in the raw material and the band at $1200 \mathrm{~cm}^{-1}$ ( $\mathrm{C}-\mathrm{O}$ and $\mathrm{C}=\mathrm{O}$ stretching) was more intense in the combined acid and alkaline, combined hydrothermal and alkaline and peroxide pretreatments.

Ether and ester bonds could be observed in greater intensity (bands 1150,1100, 1050 and 1030 $\mathrm{cm}^{-1}$ ) in the bagasse subjected to the combined acid and alkaline, combined hydrothermal and alkaline and peroxide pretreatments, but not in the alkaline pretreatment and in the raw material. Table 2 shows the main organic groups found in the raw material and in the solid fraction of the pretreated bagasse.

Table 2: Organics groups found in the raw material and in the solid fraction of the pretreated bagasse.

\begin{tabular}{|c|c|c|}
\hline $\mathbf{c m}^{-1}$ & Organic groups & References \\
\hline 3350 & $\mathrm{O}-\mathrm{H}$ & $\begin{array}{l}\text { Xu et al., (2006), } \\
\text { Camargo et al.,(2012), } \\
\text { Filho et al., (2007) }\end{array}$ \\
\hline 2900 & $\mathrm{C}-\mathrm{H}$ & $\begin{array}{l}\text { Camargo et al., (2011), } \\
\text { Riyajan and Intharit, } \\
\text { (2011), Filho et al., } \\
(2007)\end{array}$ \\
\hline 2850 & $\mathrm{OCH}_{3}$ & Camargo et al., (2011) \\
\hline 1710 & HO-C $=\mathrm{O}$ carboxylic acid & Guo et al., (2009) \\
\hline 1620 & $\mathrm{C}=\mathrm{O}$ ketone & Guo et al., (2009) \\
\hline 1600 & $\mathrm{C}-\mathrm{H}$ vibration of aromatic ring & Guo et al., (2009) \\
\hline 1500 & $\mathrm{C}-\mathrm{H}$ vibration of aromatic ring & Guo et al., (2009) \\
\hline 1410 & $\mathrm{C}-\mathrm{H}$ vibration of aromatic ring & Guo et al., (2009) \\
\hline 1390 & O-H phenolic & Xu et al., (2006) \\
\hline 1360 & $\mathrm{O}-\mathrm{H}$ phenolic & Xu et al., (2006) \\
\hline 1250 & $\mathrm{C}-\mathrm{C}$ & Xu et al., (2006) \\
\hline 1200 & $\mathrm{C}-\mathrm{O}$ and $\mathrm{C}=\mathrm{O}$ stretching & Sun et al., (2000) \\
\hline 1150 & $\mathrm{O}-\mathrm{C}=\mathrm{O}$ & Guo et al., (2009) \\
\hline 1100 & $\mathrm{O}-\mathrm{C}=\mathrm{O}$ & $\begin{array}{l}\text { Riyajan and Intharit, } \\
\text { (2011) }\end{array}$ \\
\hline 1030 & $\mathrm{C}-\mathrm{O}-\mathrm{C}$ & $\mathrm{Xu}$ et al., (2006) \\
\hline 1000 & $\mathrm{C}-\mathrm{O}-\mathrm{C}$ & Mancera et al., (2010) \\
\hline 850 & $\begin{array}{l}\beta \text {-glucosidic bonds between } \\
\text { sugars }\end{array}$ & Xu et al., (2006) \\
\hline
\end{tabular}

Although similarities were noted in the external morphologies of the bagasse among the pretreatments, the organics structures seem to be quite different. Thus, the FTIR study was important to supplement the information that could not be obtained solely by the morphological study. The organic structure of the biomass subjected to the alkaline pretreatment was similar to the raw material, while the other pretreatments resulted in a very different organic structure. Figure 4 and Table 3 show the results of the X-ray diffraction analysis carried out to evaluate the crystallinity degree of the raw and pretreated bagasse. All samples presented the same diffraction pattern, with the highest peak in the 002 crystallographic plane representing the crystalline cellulose region (Rodrigues et al., 2007). 


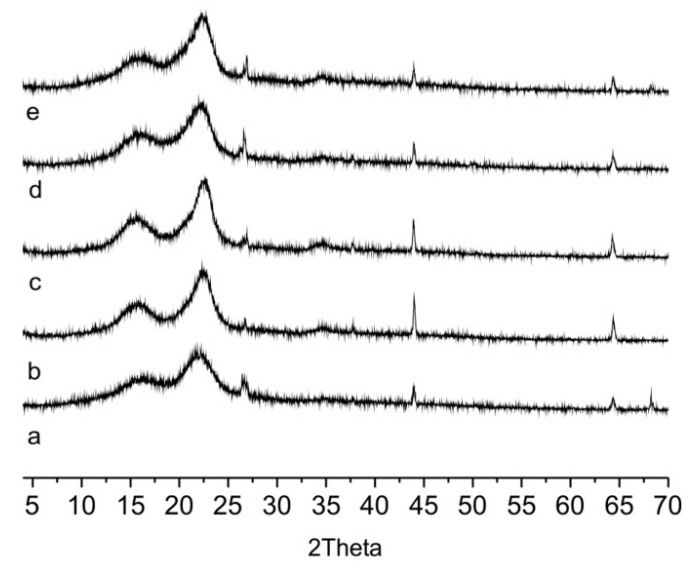

Figure 4: Diffractograms of the raw material and of the solid fraction after the pretreatment processes of the sugarcane bagasse: (a) raw material; (b) bagasse after combined acid and alkaline pretreatment; (c) bagasse after combined hydrothermal and alkaline pretreatment; (d) bagasse after alkaline pretreatment; and (e) bagasse after peroxide pretreatment.

Table 3: Crystallinity index of the raw material and of the solid fraction after the pretreatment processes of the sugarcane bagasse.

\begin{tabular}{|l|c|}
\hline Pretreatment & CI (\%) \\
\hline None (raw material) & 49.32 \\
Combined acid and alkaline & 63.54 \\
Combined hydrothermal and alkaline & 69.96 \\
Alkaline & 55.51 \\
Peroxide & 60.59 \\
\hline
\end{tabular}

Crystallinity is strongly influenced by the biomass composition. The raw material presented the lowest relative crystallinity, because it has a higher content of hemicellulose and lignin, which are amorphous (Xu et al., 2007).

The X-ray assays corroborate the compositional analyses. The bagasses with lower content of lignin and hemicellulose were the bagasse that presented higher crystallinity, as can be noted for the bagasses subjected to the combined acid and alkaline and combined hydrothermal and alkaline pretreatments.

Studying the crystallinity index of the cellulose, which is a part of the lignocellulose complex, is too complicated because the others components, hemicellulose and lignin, can influence directly in the result. In this study, if the CI of the solid fraction of the pretreated bagasse were lower than the CI of the raw material, even with hemicellulose and lignin removal, it could be evidence that the $\mathrm{CI}$ of the cellulose was modified. However, it was the opposite, the CI of the pretreated bagasse was higher than that of the raw material. This indicates that the CI results from modification of the composition of the pretreated bagasse.

Table 4 shows the results of cellulose conversion into glucose and the reducing sugars content after enzymatic hydrolysis of the pretreated bagasse. The peroxide pretreatment presented the highest cellulose conversion and the highest glucose content in the hydrolytic product. The alkaline pretreatment produced the highest amount of xylose and cellobiose. This result proves that the amount of hemicellulose present in the lignocellulose material was not able to reduce the cellulose conversion. Therefore, the acid or hydrothermal pretreatment that were used to remove hemicellulose from the lignocellulose material are not required.

Cellobiose production was higher for the alkaline pretreatment. Cellobiose may inhibit cellulose hydrolysis, but the results do not show a high degree of inhibition. FTIR results (Table 2 and Figure 3) show that the bagasse subjected to alkaline pretreatment presented the lowest amount of phenolic $\mathrm{OH}$ group, which may have favored the hydrolysis process, even though the bagasse subjected to alkaline pretreatment had a smaller relative amount of cellulose and higher amount of hemicellulose than the other bagasses.

The cellulose conversion results are in accordance with literature (Barcelos et al., 2011; Macedo et al., 2011; Carvalho et al., 2013; Idrees et al., 2014). Even working only with cellulases and $\beta$-glucosidase enzymes without xylanases or hemicellulase enzyme supplementation, it was possible to produce a high quantity of xylose in the enzymatic hydrolysis using the bagasse subjected to the alkaline pretreatment. This result induce that the mix of enzymes used may contain small amounts of xylanases or hemicellulases, which were not quantified in this work, or the xylose was released into the medium when the lignocellulosic matrix was disrupted by the action of cellulases and $\beta$-glucosidase enzymes. However, the second explanation is more appropriate because a high hemicellulose content was obtained in the solid fraction of the bagasse subjected to the peroxide pretreatment, but a low production of xylose was observed after enzymatic hydrolysis. Thus, the modified structure of the bagasse subjected to the alkaline pretreatment led to a higher xylose production.

Calculations were carried out to determine the global yield of xylose following a procedure similar to that for the calculation of the global yield of glucose. This calculation were carried out given the large amount of xylose that was produced (Figure 5). The highest global yields to glucose and xylose were observed when applying the alkaline pretreatment before enzymatic hydrolysis. 
Table 4: Conversion of cellulose into glucose and reducing sugars content after the enzymatic hydrolysis.

\begin{tabular}{|l|c|c|r|r|}
\hline Pretreatment & $\begin{array}{c}\text { Conversion } \\
(\mathbf{\%})\end{array}$ & $\begin{array}{c}\text { Glucose } \\
(\mathbf{g} / \mathbf{L})\end{array}$ & \multicolumn{1}{c|}{$\begin{array}{c}\text { Cellobiose } \\
(\mathbf{g} / \mathbf{L})\end{array}$} & \multicolumn{1}{c|}{$\begin{array}{c}\text { Xylose } \\
(\mathbf{g} / \mathbf{L})\end{array}$} \\
\hline Combined acid and alkaline & $49.50 \pm 1.4$ & $20.89 \pm 0.87$ & $1.04 \pm 0.09$ & $2.39 \pm 0.65$ \\
Combined hydrothermal and alkaline & $35.65 \pm 2.6$ & $15.22 \pm 1.56$ & $0.58 \pm 0.03$ & $1.26 \pm 0.05$ \\
Alkaline & $82.28 \pm 3.4$ & $25.79 \pm 3.21$ & $10.29 \pm 1.45$ & $15.58 \pm 2.34$ \\
Peroxide & $85.15 \pm 1.8$ & $33.87 \pm 0.54$ & $3.76 \pm 0.34$ & $3.73 \pm 0.78$ \\
\hline
\end{tabular}

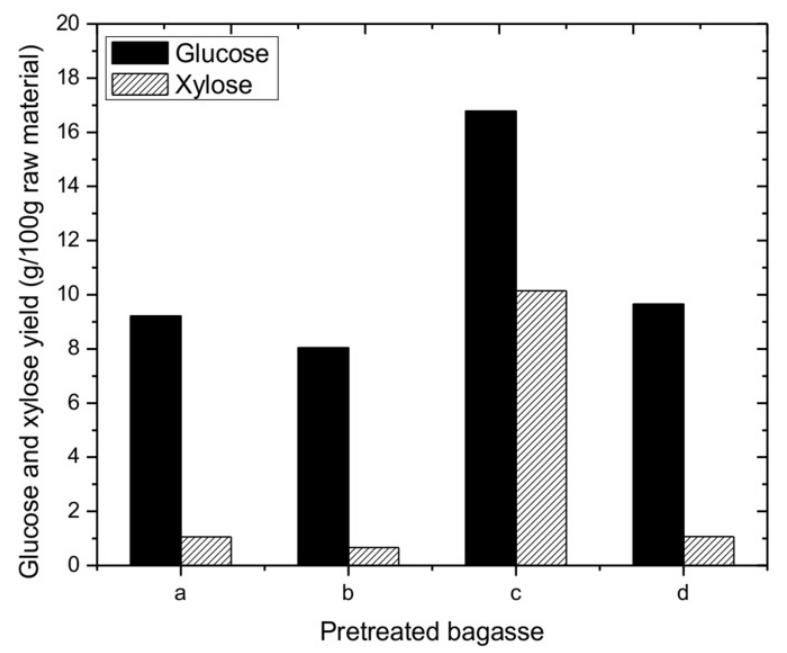

Figure 5: Global yields of glucose and xylose. (a) bagasse after combined acid and alkaline pretreatment; (b) bagasse after combined hydrothermal and alkaline pretreatment; (c) bagasse after alkaline pretreatment; and (d) bagasse after peroxide pretreatment.

\section{CONCLUSION}

The process of alkaline pretreatment (with sodium hydroxide) followed by enzymatic hydrolysis was the best option to enhance the production of glucose, with the advantage of also producing high amounts of xylose that can also be converted into ethanol.

The combination of the alkaline pretreatment with acid or hydrothermal pretreatments did not enhance further the production of glucose or even xylose. As such, the use of the alkaline pretreatment alone is interesting since a second pretreatment step is not required. Consequently, this option reduces the amount of reagents that are used and reduces the generation of waste.

The waste generated by the process can be considered to be by-products since the pentoses that are produced can be also used in the production of ethanol and lignin can be used to produce energy.

\section{ACKNOWLEDGMENT}

The authors thank CNPq and CAPES for financial support, Novozymes for donating the enzymes, the Center for Study on Oil and Gas projects funded by CTPETRO-INFRAI and FINEP/LIEM for the SEM analyzes and the Laboratory of Enzyme Technology for the hydrothermal pretreatment assays.

\section{REFERENCES}

Abril, D., Medina, M., and Abril, A., Sugar cane bagasse prehydrolysis using hot water. Braz. J. Chem. Eng., 29, 31-38 (2012).

Alves, E. F., Bose, S. K., Francis, R. C., Colodette, J. L., Lakovlev, M., Van Heiningen, A., Carbohydrate composition of eucalyptus, bagasse and bamboo by a combination of methods. Carbohyd. Polyme., 82, 1097-1101 (2010). 
Amendola, D., Faveri, D. M., Egues, I., Serrano, L., Labidi, J., Spigno, G., Autohydrolysis and organosolv process for recovery of hemicelluloses, phenolic compounds and lignin from grape stalks. Bioresour. Technol., 107, 267-274 (2012).

Asgher, M., Ahmad, Z., Iqbal, H. M. N., Alkali and enzymatic delignification of sugarcane bagasse to expose cellulose polymers for saccharification and bio-ethanol production. Ind. Crop Prod., 44, 488-495 (2013).

Barcelos, C. A., Maeda, R. N., Betancur, G. J. V., and Pereira Jr. N., Ethanol production from sorghum grains [Sorghum bicolor (L.) Moench]: Evaluation of the enzymatic hydrolysis and the hydrolysate fermentability. Braz. J. Chem. Eng., 28, 597-604 (2011).

Betiku, E., Adetunji, O. A., Ojumu, T. V., and Solomon, B. O., A comparative study of the hydrolysis of gamma irradiated lignocelluloses. Braz. J. Chem. Eng., 26, 251-255 (2009).

Benko, Z., Siika-Ahob, M., Viikari, L., Reczeya, K., Evaluation of the role of xyloglucanase in the enzymatic hydrolysis of lignocellulosic substrates. Enzyme Microb. Technol., 43, 109-114 (2008).

Bommarius, A. S., Katona, A., Cheben, S. E., Patel, A. S., Ragauskas, A. J., Knudson, K., Pu, Y., Cellulase kinetics as a function of cellulose pretreatment. Metabolic Eng., 10, 370-381 (2008).

Boussarsar, H., Roge, B., Mathlouthi, M., Optimization of sugarcane bagasse conversion by hydrothermal treatment for the recovery of xylose. Bioresour. Technol., 100, 6537-6542 (2009).

Brigida, A. I. S., Calado, V. M. A., Gonçalves, L. R. B., Coelho, M. A. Z., Effect of chemical treatments on properties of green coconut fiber. Carbohydrate Polymers, 79 832-838 (2010).

Camargo, F. A., Innocentini-Mei, L. H., Lemes, A. P., Moraes, S. G., Duran, N., Processing and characterization of composites of poly(3hydroxybutyrateco-hydroxyvalerate) and lignin from sugar cane bagasse. J. Compos. Mater., 46, 417-425 (2012).

Carvalho, M. L., Sousa Jr. R., Rodríguez-Zúñiga, U. F., Suarez, C. A. G., Rodrigues, D. S., Giordano, R. C. and Giordano, R. L. C., Kinetic study of the enzymatic hydrolysis of sugarcane bagasse. Braz. J. Chem. Eng., 30, 437-447 (2013).

Chang, V. and Holtzapple, M., Fundamental factors affecting biomass enzymatic reactivity. Appl. Biochem. Biotechnol., 84-86, 5-37 (2000).

Chen, X., Lawoko, M., Van Heiningen, A., Kinetics and mechanism of autohydrolysis of hardwoods. Bioresour. Technol., 101, 7812-7819 (2010).

Cullity, B. D., Element of X-Ray Diffraction. Osmania
University Library, USA (1956).

Egues, I., Sanchez, C., Mondragon, I., Labidi, J., Effect of alkaline and autohydrolysis processes on the purity of obtained hemicelluloses from corn stalks. Bioresour. Technol., 103, 239-248 (2012).

Filho, G. R., Assuncao, R. M. N., Vieira, J. G., Meireles, C. S., Cerqueira, D. A., Barud, H. S. S., Ribeiro, J. L., Messaddeq, Y., Characterization of methylcellulose produced from sugar cane bagasse cellulose: Crystallinity and thermal properties. Polym. Degrad. Stab., 92, 205-210 (2007).

Gould, J. M., Studies on the mechanism of alkaline peroxide delignification of agricultural residues. Biotechnol. Bioeng., 27, 225-231 (1985).

Gouveia, E. R., Nascimento, R. T., Souto-Maior, A. M., Rocha, G. J. M., Validação de metodologia para a caracterização química de bagaço de canade-açúcar. Quim. Nova, 32, 1500-1503 (2009). (In Portuguese).

Guo, G. L., Hsu, D. C., Chen, W. H., Chen, W. H., Hwang, W. S., Characterization of enzymatic saccharification for acid-pretreated lignocellulosic materials with different lignin composition. Enzyme Microb. Technol., 45, 80-87 (2009).

Hofsetz, K., Silva, M. A., Brazilian sugarcane bagasse: Energy and non-energy consumption. Biomass Bioenergy, 46, 564-573 (2012).

Idrees, M., Adnan, A., Bokhari, S. A. and Qureshi, F. A., Production of fermentable sugars by combined chemo-enzymatic hydrolysis of cellulosic material for bioethanol production. Braz. J. Chem. Eng., 31, 355-363 (2014).

Lee, J. M., Shi, J., Venditti, R. A., Jameel, H., Autohydrolysis pretreatment of Coastal Bermuda grass for increased enzyme hydrolysis. Bioresour. Technol., 100, 6434-6441 (2009).

Luo, L., Voet, E. V. D., Huppes, G., Biorefining of lignocellulosic feedstock - technical, economic and environmental considerations. Bioresour. Technol., 101, 5023-5032 (2010).

Macedo, A. L., Santos, R. S., Pantoja, L. and Santos, A. S., Pequi cake composition, hydrolysis and fermentation to bioethanol. Braz. J. Chem. Eng., 28, 9-15 (2011).

Mancera, A., Fierro, V., Pizzi, A., Dumarçay, S., Gerardin, P., Velasquez, J., Quintana, G., Celzard, A., Physicochemical characterisation of sugar cane bagasse lignin oxidized by hydrogen peroxide. Polym. Degrad. Stab., 95, 470-476 (2010).

Martin, J. F. G., Cuevas, M., Bravo, V., Sanchez, S., Ethanol production from olive prunings by autohydrolysis and fermentation with Candida tropicalis. Renew Energ., 35, 1602-1608 (2010).

Pan, X. J., Role of functional groups in lignin inhibi- 
tion of enzymatic hydrolysis of cellulose to glucose. J. Biobased Mater Bioenergy, 2, 25-32 (2008).

Rabelo, S. C., Amezquita, F. N. A., Andrade, R. R., Filho, R. M., Costa, A. C., Ethanol production from enzymatic hydrolysis of sugarcane bagasse pretreated with lime and alkaline hydrogen peroxide. Biomass Bioenergy, 35, 2600-2607 (2011).

Reiner, L., Scanning Electron Microscopy: Physics of Image Formation and Microanalysis. New York (2010).

Riyajan, S. and Intharit, I., Characterization of modified bagasse and investigation properties of its novel composite. J. Elast. Plast., 43, 513-528 (2011).

Rocha, M. V. P., Produção de Bioetanol a partir de Pedúnculo de Caju (Anacardium occidentale L.) por Fermentação Submersa. Ph.D. Thesis, Universidade Federal do Rio Grande do Norte (2010). (In Portuguese).

Rodrigues, F. G., Assunção, R. M. N., Vieira, J. G., Meireles, C. S., Cerqueira, D. A., Barud, H. S., Ribeiro, S. J. L., Messaddeq, Y., Characterization of methylcellulose produced from sugar cane bagasse cellulose: Crystallinity and thermal properties. Polym. Degrad. Stab., 92, 205-210 (2007).

Rohowsky, B., Habler, T., Gladis, A., Remmele, E., Schieder, D., Faulstich, M., Feasibility of simultaneous saccharification and juice co-fermentation on hydrothermal pretreated sweet sorghum bagasse for ethanol production. Appl. Energy, 102, 211-219 (2013).

Ruiz, H. A., Cerqueira, M. A., Silva, H. D., Rodriguez-Jasso, R. M., Vicente, A. A., Teixeira, J. A., Biorefinery valorization of autohydrolysis wheat straw hemicellulose to be applied in a polymerblend film. Carbohydr. Polym., 92, 2154-2162 (2013a).

Ruiz, H. A., Rodriguez-Jasso, R. M., Fernandes, B. D., Vicente, A. A., Teixeira, J. A., Hydrothermal processing, as an alternative for upgrading agriculture residues and marine biomass according to the biorefinery concept: A review. Renew Sus. Ener. Rev., 2, 35-51 (2013b).

Schell, D. J., Farmer, J., Newman, M., McMillan, J. D., Dilute sulfuric acid pretreatment of corn stover in pilot-scale reactor - investigation of yields, kinetics, and enzymatic digestibilities of solids. Appl. Biochem. Biotechnol., 105, 69-85 (2003).

Segal, L., Creely, J. J., Martin, A. E., Conrad, C. M.,
An empirical method for estimating the degree of crystallinity of native cellulose using the X-ray diffractometer. Text Res. J., 29, 764-786 (1959).

Selig, M., Weiss, N., Ji, Y., Enzymatic Saccharification of Lignocellulosic Biomass, Laboratory Analytical Procedure (LAP). Technical Report, NREL, p. 8 (2008).

Silva, V. F. N., Arruda, P. V., Felipe, M. G. A., Goncalves, A. R., Rocha, G. J. M., Fermentation of cellulosic hydrolysates obtained by enzymatic saccharification of sugarcane bagasse pretreated by hydrothermal processing. J. Ind. Microbiol. Biotechnol., 38, 809-817 (2011).

Silverstein, R. A., Chen, Y., Sharma-Shivappa, R. R., Boyette, M. D. J. O., A comparison of chemical pretreatment methods for improving saccharification of cotton stalks. Bioresour. Technol., 98, 3000-3011 (2007).

Sluiter, A., Ruiz, R., Scarlata, C., Sluiter, L., Templeton, D., Determination of Extractives in Biomass. Laboratory Analytical Procedure (LAP). Technical Report, NREL, p. 12 (2008).

Smith, B. C., Fundamentals of Fourier Transform Infrared Spectroscopy. CRC Press, Boca Raton, FL, USA (1996).

Sun, R. C., Tomkinson, J., Wang, S. Q., Zhu, W., Characterization of lignins from wheat straw by alkaline peroxide treatment. Polym. Degrad. Stab., 67, 101-109 (2000).

Sun, Y. and Cheng, J., Hydrolysis of lignocellulosic materials for ethanol production: A review. Bioresour. Technol., 83, 1-11 (2002).

Vasquez, M. P., Silva, J. N. C., Souza, M. B. J. R., Pereira, N. Jr., Enzymatic hydrolysis optimization to ethanol production by simultaneous saccharification and fermentation. Appl. Biochem. Biotechnol., 136-140, 141-154 (2007).

Xu, F., Sun, J., Liub, X. C. F., Sunb, R. C., Comparative study of alkali- and acidic organic solvent-soluble hemicellulosic polysaccharides from sugarcane bagasse. Carbohydr. Res., 34, 253-261 (2006).

Xu, Z., Wang, Q., Jianga, Z. H., Yang, X., Ji, Y., Enzymatic hydrolysis of pretreated soybean straw. Biomass Bioenergy, 31, 162-167 (2007).

Zhao, X., Zhou, Y., Zheng, G., Liu, D., Microwave pretreatment of substrates for cellulase production by solid-state fermentation. Appl. Biochem. Biotechnol., 160, 1557-1571 (2010). 